Supporting Information

\title{
Helical Folding of Alkanes in a Self- Assembled Cylindrical Capsule
}

\section{Alessandro Scarso, Laurent Trembleau and Julius Rebek Jr.}

Determination of temperature coefficients:

$n-\mathrm{C}_{5} \mathrm{H}_{12} @ \mathbf{1}_{2}$ :

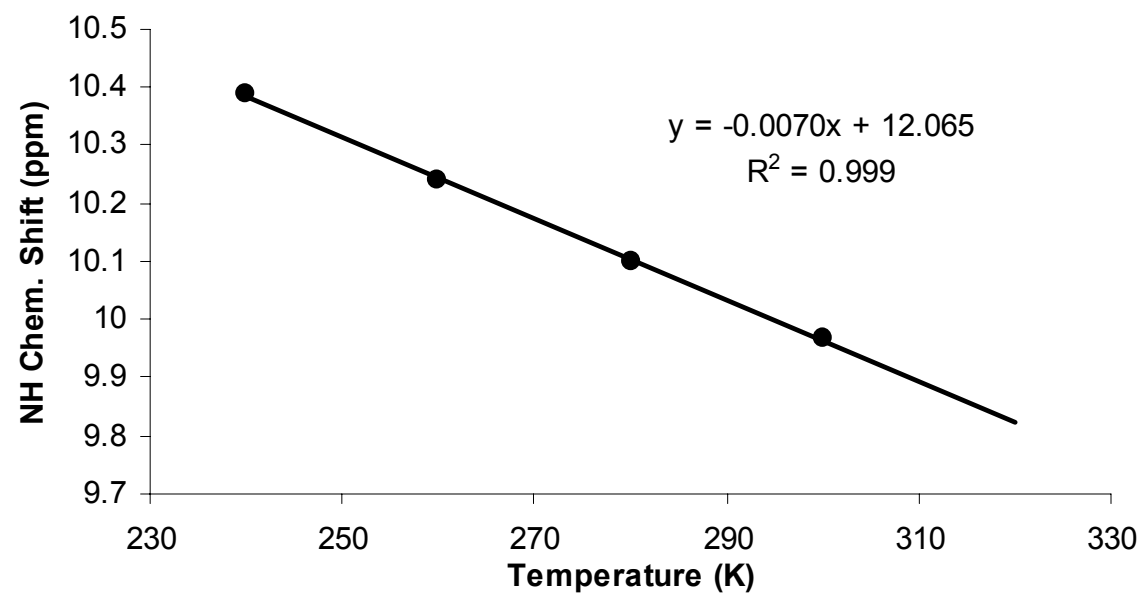

$n-\mathrm{C}_{6} \mathrm{H}_{14} @ \mathbf{1}_{2}$ :

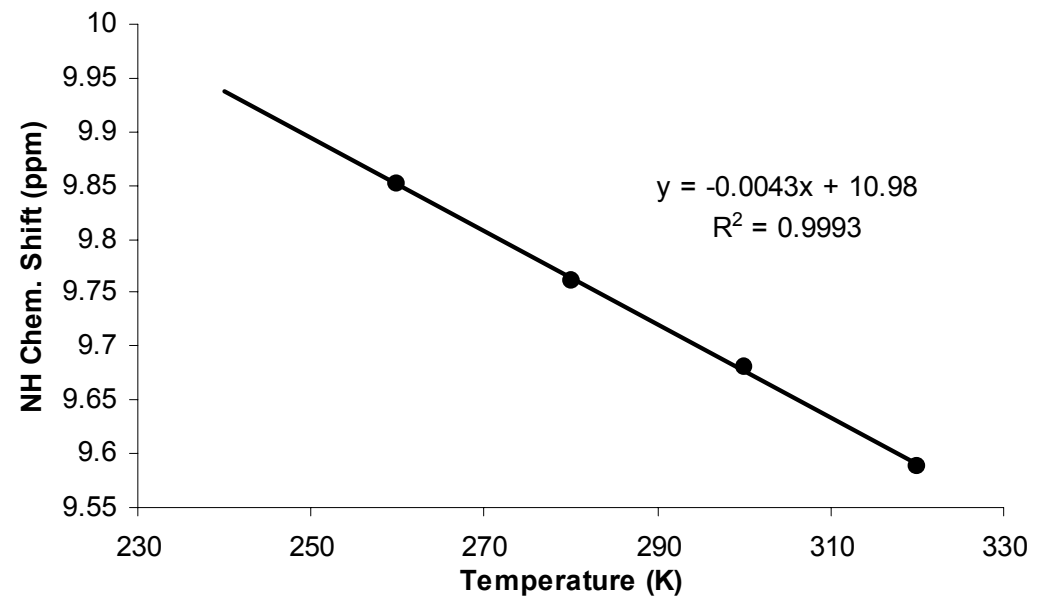


n- $\mathrm{C}_{7} \mathrm{H}_{16} @ \mathbf{1}_{2}$ :

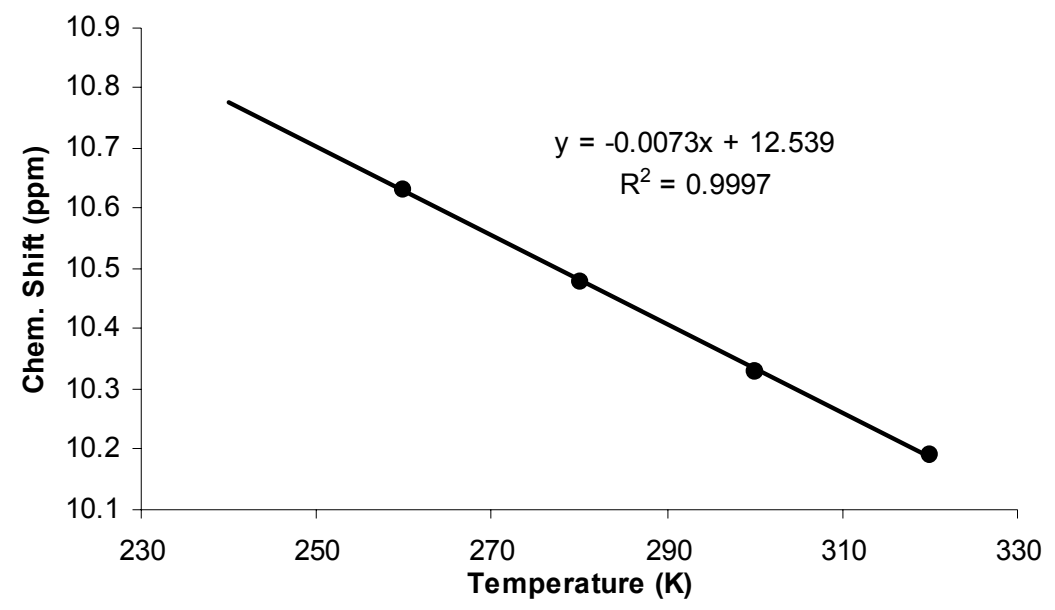

$n-\mathrm{C}_{8} \mathrm{H}_{18} @ \mathbf{1}_{2}:$

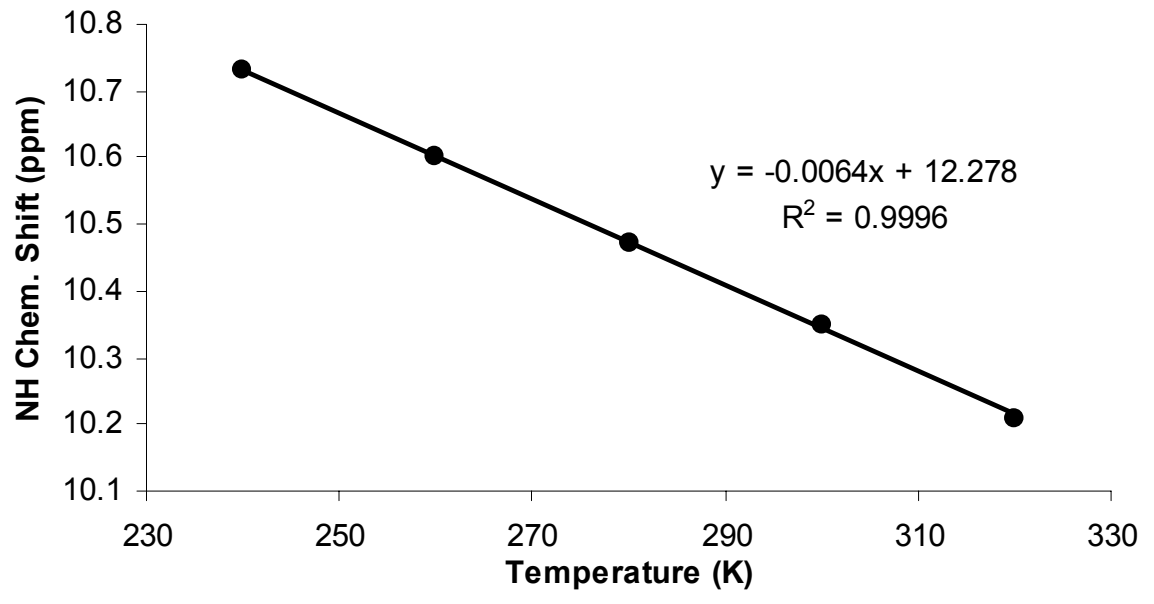

n- $\mathrm{C}_{9} \mathrm{H}_{20} @ \mathbf{1}_{2}$ :

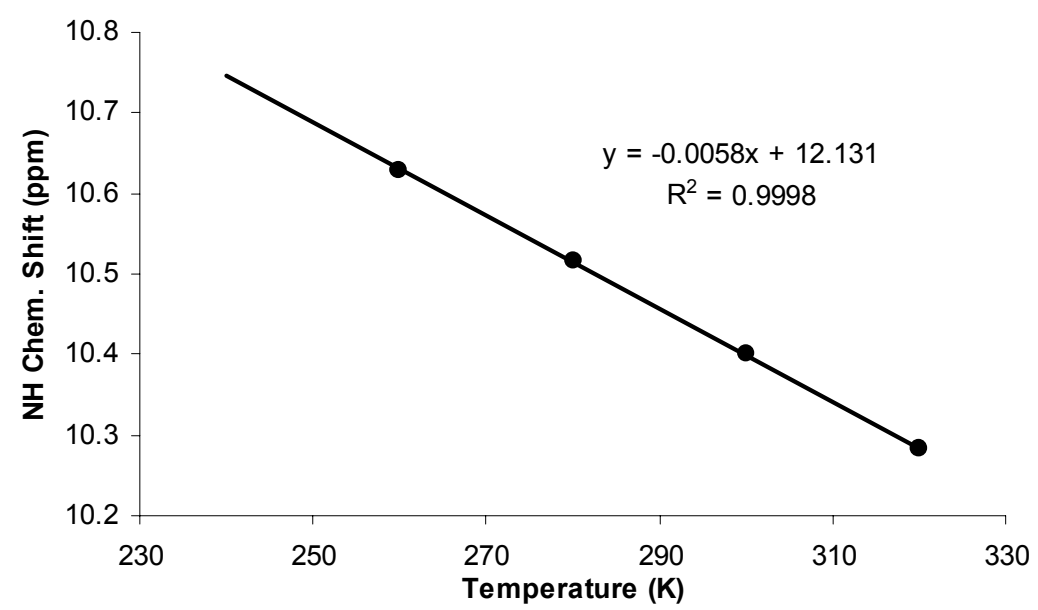


n- $\mathrm{C}_{10} \mathrm{H}_{22} @ \mathbf{1}_{\mathbf{2}}$ :

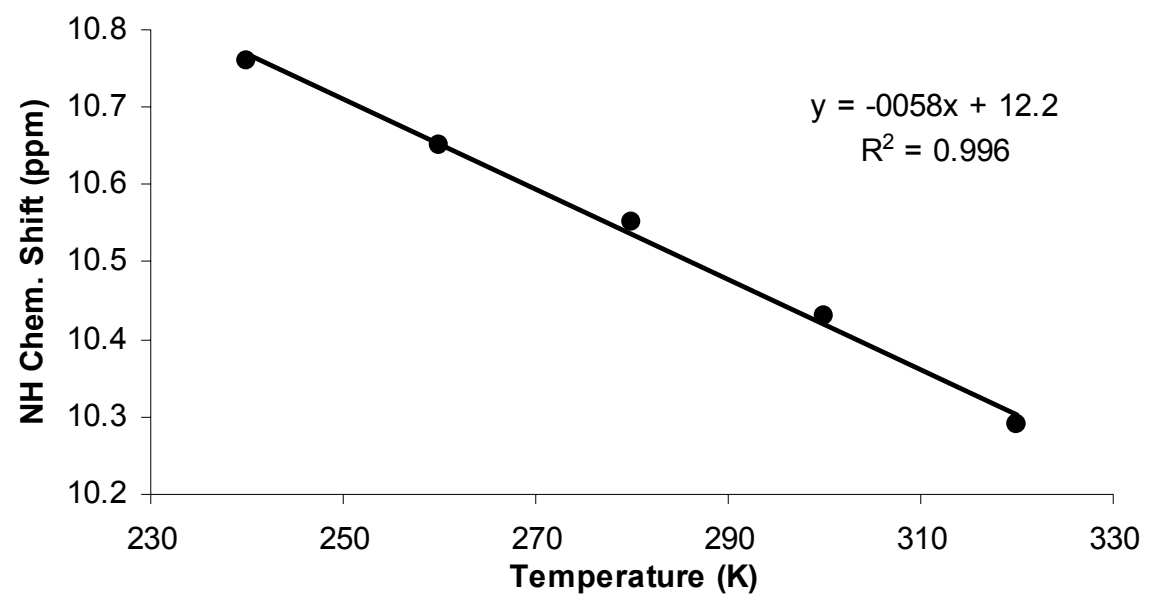

n- $\mathrm{C}_{11} \mathrm{H}_{24} @ \mathbf{1}_{2}$ :

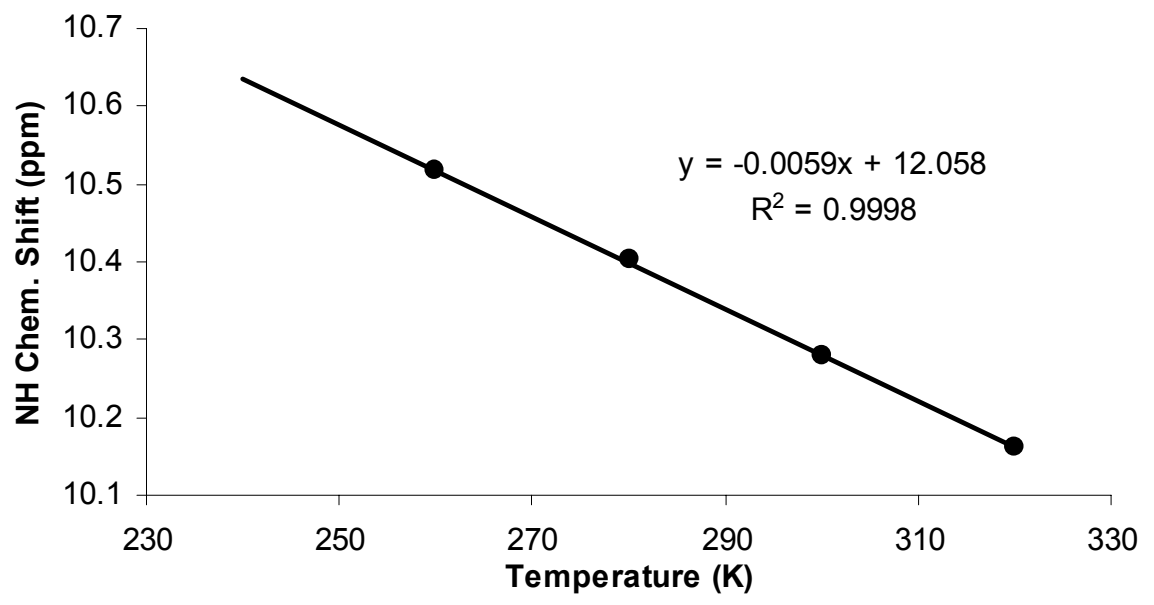

n- $\mathrm{C}_{12} \mathrm{H}_{26} @ \mathbf{1}_{2}$ :

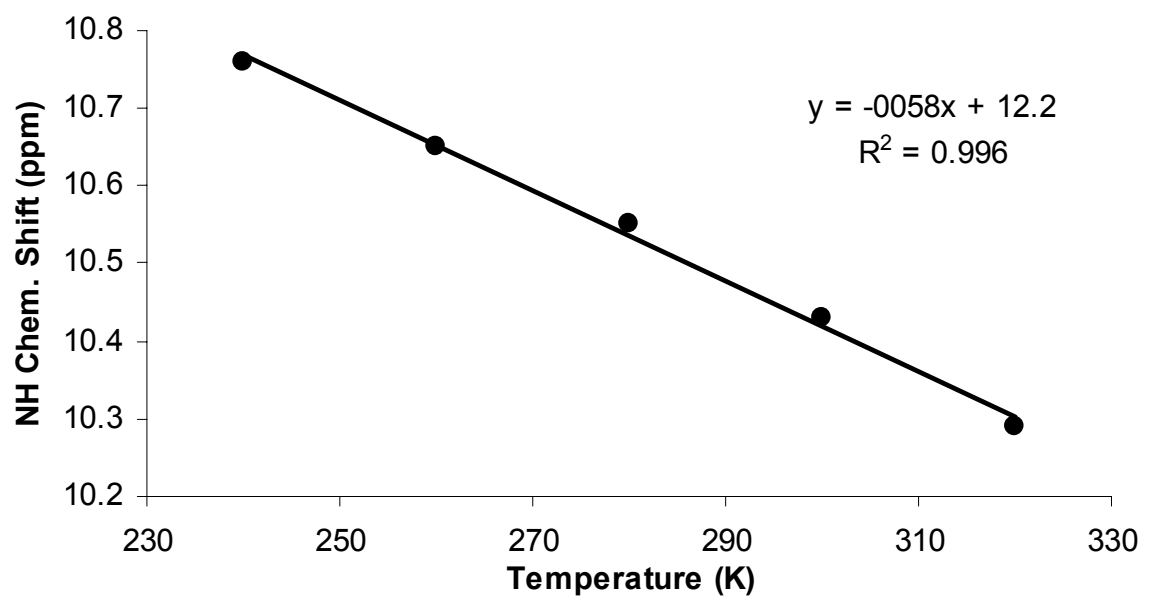


n- $\mathrm{C}_{13} \mathrm{H}_{28} @ \mathbf{1}_{2}$ :

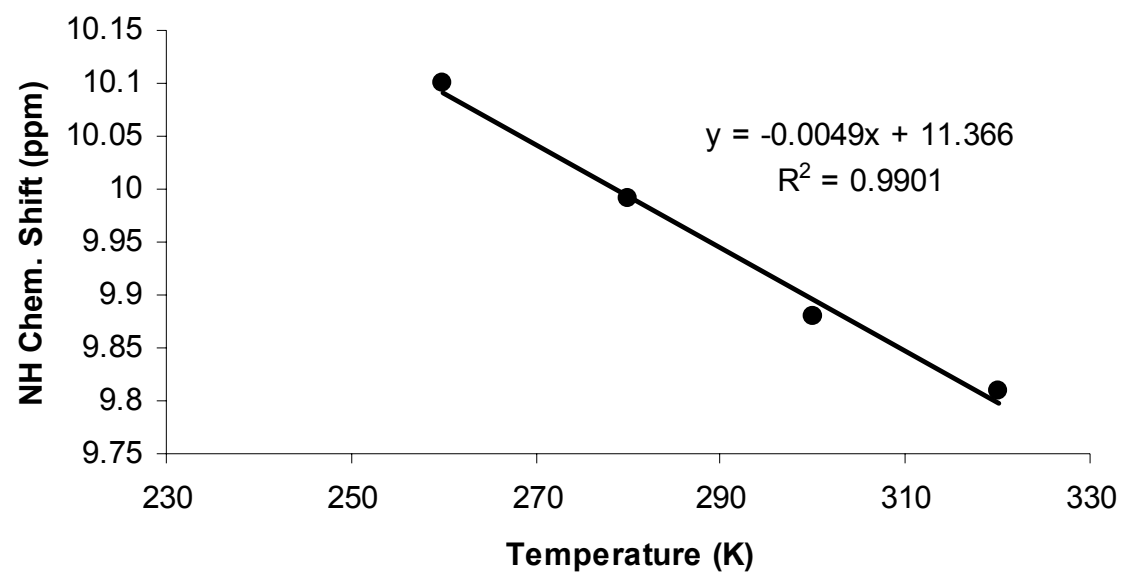

n- $\mathrm{C}_{14} \mathrm{H}_{30} @ \mathbf{1}_{2}$ :

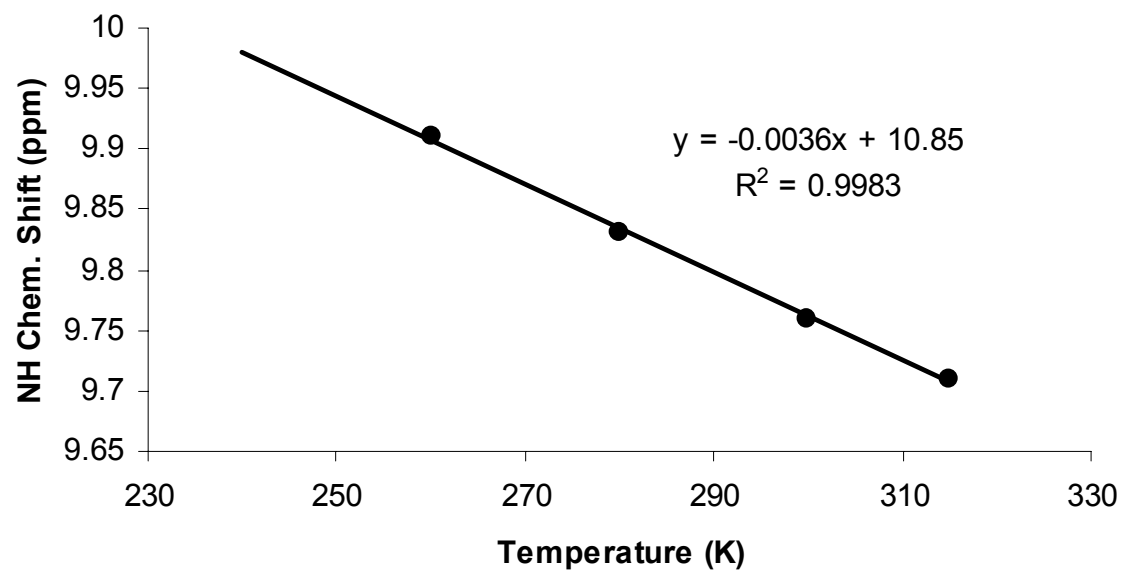

n- $\mathrm{C}_{14} \mathrm{H}_{28} @ \mathbf{1}_{2}$ :

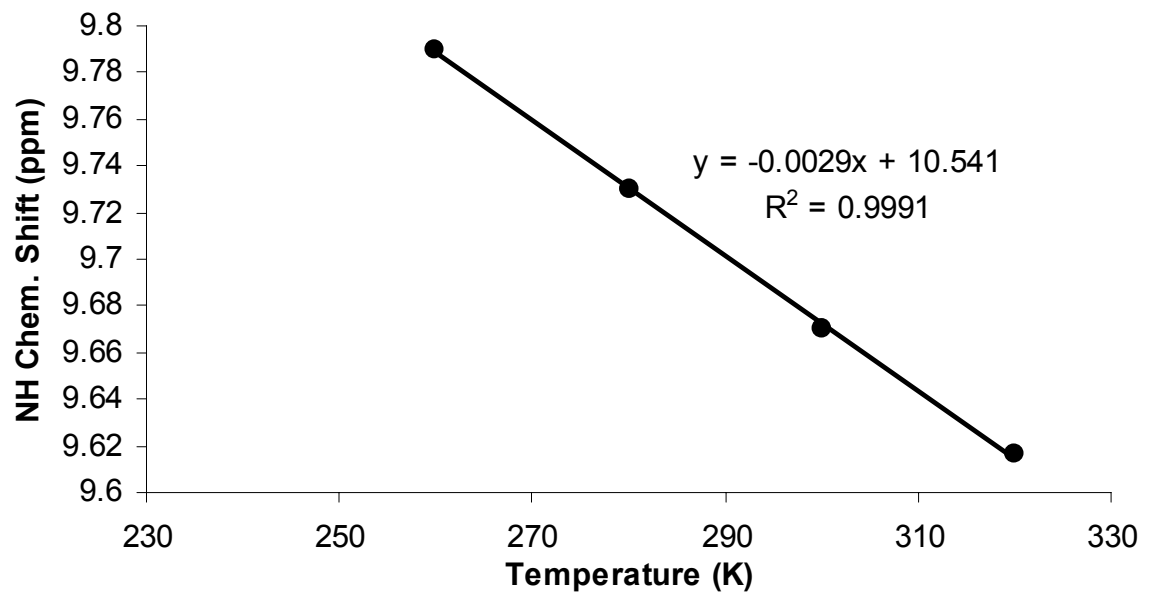


Competitive complexation of $n-\mathrm{C}_{10} \mathrm{H}_{22}$ and $n-\mathrm{C}_{11} \mathrm{H}_{24} @ 1_{2}\left({ }^{1} \mathrm{H}\right.$ NMR spectra of the imide $\mathrm{NH}$ region of the capsule : $n-\mathrm{C}_{10} \mathrm{H}_{22}(10.43 \mathrm{ppm})$ and $\left.n-\mathrm{C}_{11} \mathrm{H}_{24}(10.31 \mathrm{ppm})\right)$.

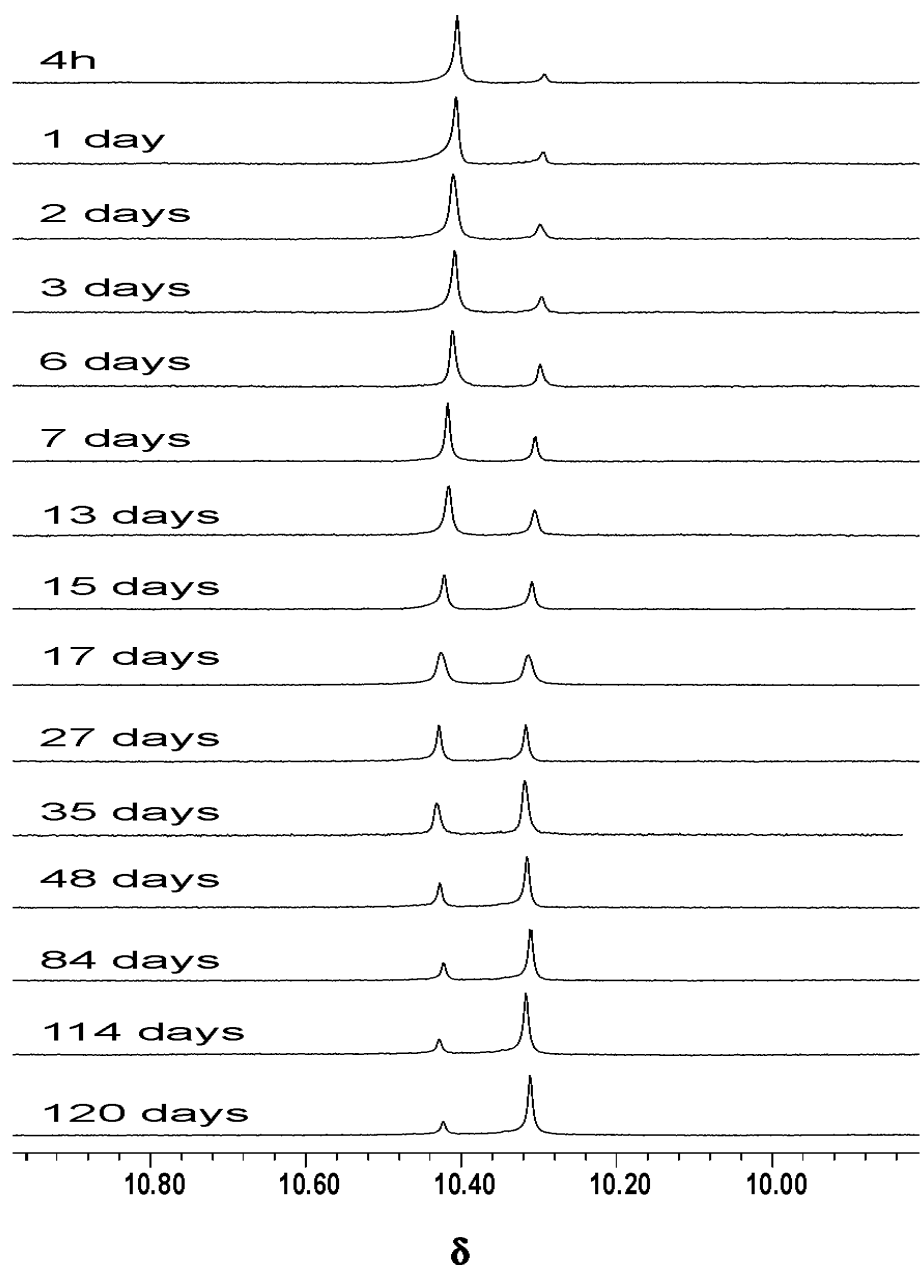

